\title{
Promotion and Tuning of the Electrochemical Reduction of Hetero- and Homobimetallic Zinc Complexes
}

\author{
Shaun R. Kelsey, ${ }^{[a]}$ Amit Kumar, ${ }^{[a]}$ Allen G. Oliver,${ }^{[b]}$ Victor W. Day, ${ }^{[a]}$ and James D. Blakemore ${ }^{*[a]}$
}

[a] S.R. Kelsey, A. Kumar, Dr. V.W. Day and Prof. J.D. Blakemore Department of Chemistry

University of Kansas

1567 Irving Hill Rd, Lawrence, KS 66045

E-mail: blakemore@ku.edu

[b] Dr. A.G. Oliver

Department of Chemistry and Biochemistry

University of Notre Dame

149 Stepan Chemistry, Notre Dame, IN 46556 USA

Supporting information for this article is given via a link at the end of the document.

\begin{abstract}
Compounds containing multiple metals attract significant interest due to the useful redox and reactivity properties of such species. Here, the electrochemical properties of a family of macrocyclic complexes that feature a zinc(II) center paired with a second redox-inactive metal cation in heterobimetallic $\left(\mathrm{Na}^{+}, \mathrm{Ca}^{2+}\right.$, $\left.\mathrm{Nd}^{3+}, \mathrm{Y}^{3+}\right)$ motifs or a homobimetallic $\left(\mathrm{Zn}^{2+}\right)$ motif have been investigated. The new complexes were prepared via a divergent strategy, isolated, and structurally characterized by single-crystal $X$ ray diffraction (XRD) analysis. XRD results show that the structure of the complexes is modulated by the identity of the incorporated secondary metal ions. Cyclic voltammetry data reveal that ligandcentered reduction is promoted in the bimetallic complexes and that the paired metal ions synergistically influence the redox properties of the complexes. Similar to prior work from our group and others, the bimetallic complexes containing stronger Lewis acids undergo more significant reduction potential shifts; contrasting with prior work on complexes containing redox-active metals, however, the zinc(II) complexes studied here display faster electron transfer (as judged by lower reorganization energies, $\lambda$ ) when incorporating di- or tri-valent Lewis acids in contrast to monovalent (and more weakly acidic) sodium. The quantified trends in these data offer insights that help distinguish metal- versus ligand-centered reduction of bimetallic complexes.
\end{abstract}

\section{Introduction}

Chemical species containing multiple metals appear in a wide variety of contexts, and play important roles in many chemical systems. As a result, significant efforts have recently been put forth in development of multimetallic coordination complexes and understanding of their chemical and electrochemical properties. Such efforts have been bolstered by notable advances in synthetic chemistry, which have enabled assembly and isolation of well-defined structures containing multiple different metals. ${ }^{1}$ Study of such structures has enabled new insights into the diverse influences that multiple metals can have on chemical reactivity when they are placed in close proximity. ${ }^{2}$

Heterometallic complexes that pair redox-active metals with redox-inactive metals attract particular attention. ${ }^{3}$ This is due in part to their ease of preparation-most redox-inactive metal cations are diamagnetic ${ }^{4}$ and compounds containing them can often be studied by nuclear magnetic resonance (NMR) methods. ${ }^{5}$ However, more importantly, incorporation of redoxinactive metals into a common parent complex offers the appealing opportunity for tuning of redox chemistry through selection of an appropriate metal cation. Such a tuning strategy is inspired by the presence of an essential $\mathrm{Ca}^{2+}$ ion in the OxygenEvolving Complex (OEC) of Photosystem II; model work has shown that this ion serves to modulate the reduction potential of the nearby redox-active manganese centers ${ }^{6}$ and thereby enable water oxidation to occur. ${ }^{7}$ Inspired by these observations, researchers have investigated the tuning of transition-metal oxo complexes by direct interactions with metal cations that serve as Lewis acids and promote oxidation reactivity. ${ }^{8}$ Numerous other transition-metal complexes, redox processes, and catalytic reactions have been tuned with Lewis acidic metal cations in related ways, testifying to the power of this approach. ${ }^{9}$

In our own work, we have become interested in exploring the chemical and electrochemical properties of bimetallic complexes of heavier elements supported by macrocyclic, heteroditopic ligands. Such ligands feature two distinctive sites for binding of metal ions and are useful for study of heterometallic effects. Most recently, we have prepared the first series of structurally characterized heterobimetallic and macrocyclic uranyl $\left(\mathrm{UO}_{2}{ }^{2+}\right)$ compounds and used these to study the influence of incorporated redox-inactive Lewis acidic metals on the important $U^{\mathrm{V} /} / \mathrm{U}^{\mathrm{V}}$ redox manifold as well as the associated heterogeneous electron transfer kinetics. ${ }^{10}$ Building on our related work with $\mathrm{Ni}$ complexes, ${ }^{11}$ compounds incorporating strongly Lewis acidic trivalent cations undergo the greatest changes in redox chemistry and electrochemically-induced chemical reactivity, similar to findings with many transition-metal species and pioneering chemical work with actinide elements. ${ }^{12}$ Thus, rational tuning of redox-active heavy element complexes by Lewis acidic metal cations ${ }^{4}$ represents an appealing strategy for future applications in electrochemical processing of actinide elements.

In light of the importance of studies of the modulation of reduction potentials by redox-inactive cations, we were surprised to find that electrochemical studies of macrocyclic complexes containing multiple redox-inactive metals (and thus no redox-active metals) 
have not been reported. The possible involvement of ligandcentered redox events in the (electro)chemistry of such compounds originally attracted our interest in this area, since distinguishing between metal- and ligand-centered reduction events in metal complexes is an important and long-standing area of inquiry. ${ }^{13}$ More broadly, since incorporation of redox-inactive metals into heterobimetallic species has emerged as a premier method of tuning the properties of redox-active metals, we imagined that investigation of such tuning of a family of complexes containing only redox-inactive metals could provide new insights into Lewis acid-modulated chemistry. ${ }^{14,15}$

Here, we report the divergent synthesis and study of macrocyclic and bimetallic complexes of redox-inactive zinc(II) with a range of secondary redox-inactive Lewis acidic metal cations (namely, $\mathrm{Na}^{+}$, $\mathrm{Ca}^{2+}, \mathrm{Zn}^{2+}, \mathrm{Nd}^{3+}$, and $\mathrm{Y}^{3+}$ ). These redox-inactive metals span a wide range of Lewis acidity, as judged by the $p K_{a}$ values of their corresponding metal aqua cations $\left(p K_{a}=14.8\right.$ for $\mathrm{Na}^{+}, 8.3$ for $\left.\mathrm{Y}^{3+}\right) .{ }^{16}$ The family of synthesized complexes is the first structurally characterized series of bimetallic macrocyclic $\mathrm{Zn}$ (II) complexes, and thus it complements analogous series of compounds developed by our group and others containing redox-active metals. Structural characterization in concert with electrochemical studies reveal that the bimetallic compounds' ligand-centered reduction processes can be rationally tuned by incorporation of the secondary Lewis acidic metals, and that this tuning effect is engendered by the localization of the multiple redox-inactive metal ions in the macrocyclic ligand framework.

\section{Results}

\section{Synthesis and Characterization of the Bimetallic Species}

The complexes reported here are based upon ligand frameworks developed by Reinhoudt ${ }^{17,18}$ and elaborated upon by Vigato ${ }^{19}$ that feature Schiff-based binding sites appended with crown-ether-like sites. These compounds build upon the important and early structural observations ${ }^{20}$ made by Milburn, Truter, and Vickery regarding the formation of dinuclear O-bridged species ${ }^{21,22}$ with tetradentate Schiff base complexes of divalent metals. In our syntheses of complexes pairing redox-active and -inactive metals, the crown-ether-like site has proven especially useful for stable binding of the secondary metals, including mono-, di-, and trivalent redox-inactive cations. We turned to the same salophenbased ligand framework utilized in some of our prior studies ${ }^{11}$ to carry out the work described here, since salophen moieties form stable monometallic complexes of zinc(II).

Our synthetic strategy (Scheme 1) involves preparation of a common zinc(II)-containing macrocyclic salophen compound $[\mathbf{Z n}]{ }^{18}$ that can undergo divergent metalation in a subsequent step with metal triflate salts to install the secondary redox-inactive metal cations. [Zn] was prepared according to Reinhoudt and coworkers' original method by treatment of precursor $\left[\mathrm{H}_{2}, \mathrm{Ba}\right]$ with zinc(II) acetate, affording significant supplies of the desired monometallic precursor. Our strategy differs significantly from that of Yang and co-workers, wherein heterobimetallic first-row transition metal compounds have been convergently assembled. ${ }^{15 a, 23}$ We prefer divergent metalation from common monometallic precursors both because (i) it allows rapid access to a variety of bimetallic species and (ii) enables access to species incorporating trivalent Lewis acidic cations that may be otherwise inaccessible.

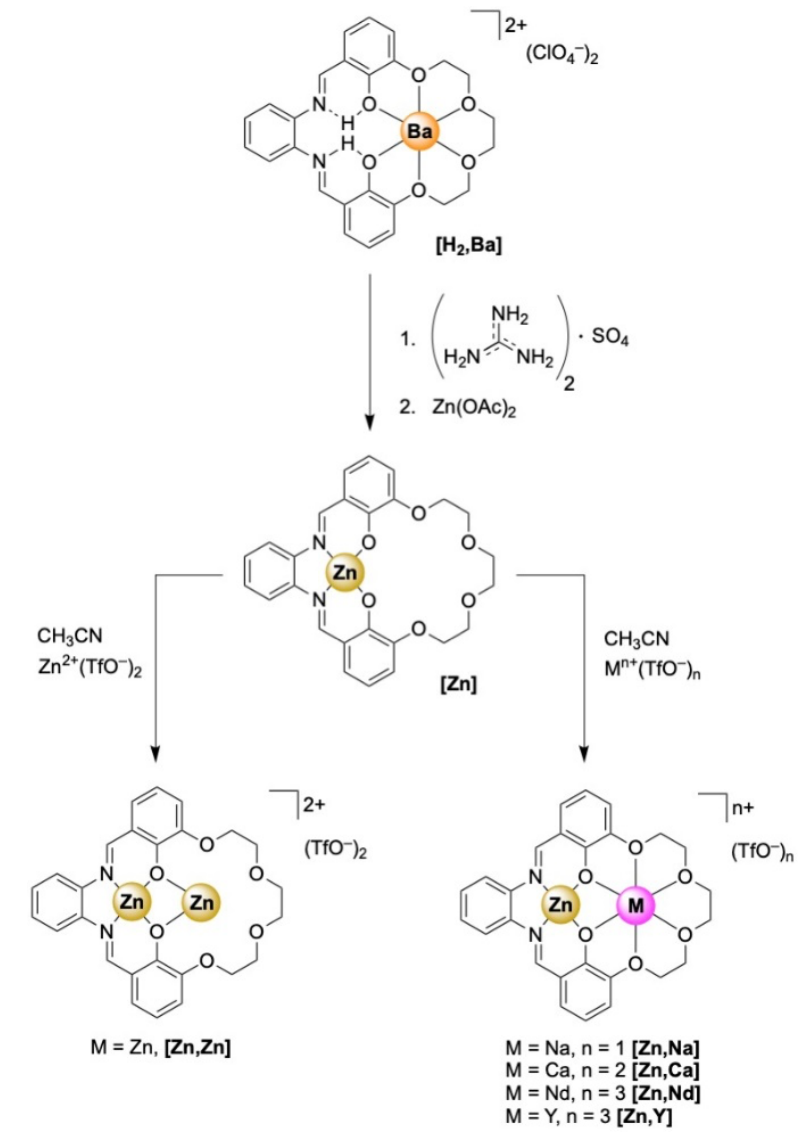

Scheme 1. Synthesis of hetero- and homo-bimetallic complexes of zinc(II) with mono-, di-, and tri-valent secondary metals.

The monometallic [Zn] complex can be synthesized by stirring 1 equiv. of $\left[\mathrm{H}_{2}, \mathrm{Ba}\right]$ with 10 equiv. of guanidinium sulfate in a biphasic water/chloroform system. Subsequent treatment of the organic layer with zinc(II) acetate affords [Zn] as an orange solid. ${ }^{1} \mathrm{H}$ NMR confirmed synthesis of this complex, indicating binding of the zinc(II) ion in the Schiff base site of our heteroditopic ligand, leaving the adjacent crown ether-like site open and poised to bind Lewis acidic metals, much like in our prior work with nickel and uranyl. ${ }^{10,11}$

The heterobimetallic complexes of the form [Zn,M] can be prepared by reaction of $[\mathbf{Z n}]$ with the corresponding metal triflate salts. Specifically, treatment of $[\mathbf{Z n}]$ with 1 equiv. of the triflate salts of $\mathrm{Na}^{+}, \mathrm{Ca}^{2+}, \mathrm{Zn}^{2+}, \mathrm{Nd}^{3+}$, and $\mathrm{Y}^{3+}$ results in the generation of 1:1 bimetallic complexes with high yields in each case. Based on their clean and uniform appearance, the ${ }^{1} \mathrm{H}$ NMR spectra (see SI, Figures S3-S17) indicate that the zinc(II) ion remains bound in the tetradentate Schiff-base site and the other ions remain bound in the crown-ether-like site in $\mathrm{CH}_{3} \mathrm{CN}$ solution (see Experimental Section for detailed synthetic procedures and full characterization). No evidence of metal-ion scrambling between the two binding sites was observed here, even for the two divalent ions $\mathrm{Zn}^{2+}$ and $\mathrm{Ca}^{2+}$ in [Zn,Ca]. This observation highlights the 
apparent utility of $[\mathbf{Z n}]$ for orthogonal metalation reactivity, even with typically promiscuous redox-inactive metal ions.

Electronic absorption spectra confirm the influence of the secondary-redox inactive metals on the electronic properties of the heterobimetallic compounds, but unfortunately offer fewer insights into the Lewis acidity-driven tuning effects than in our prior work with $\mathrm{Ni}$ and $\mathrm{U}$. In the visible region, the spectrum of [Zn] (see SI, Figure S18) is dominated by an intense feature with a wavelength of maximum absorption $\left(\lambda_{\max }\right)$ at $409 \mathrm{~nm}$ and molar absorptivity $(\varepsilon)$ of ca $13,900 \mathrm{M}^{-1} \mathrm{~cm}^{-1}$. Higher energy bands (attributable to intraligand transitions) with $\varepsilon>20,000 \mathrm{M}^{-1} \mathrm{~cm}^{-1}$ are also present in all the compounds; these undergo only minor shifts upon incorporation of the various secondary metals. Little shift in the visible band is apparent upon incorporation of weakly Lewis acidic sodium in $[\mathrm{Zn}, \mathrm{Na}]\left(\lambda_{\max }=408 \mathrm{~nm}, \varepsilon=16,300 \mathrm{M}^{-1} \mathrm{~cm}^{-1}\right)$, but incorporation of the stronger Lewis acids $\mathrm{Ca}^{2+}, \mathrm{Zn}^{2+}, \mathrm{Nd}^{3+}$, and $\mathrm{Y}^{3+}$ results in a shifting of the band to higher energies (see SI, Figures S19 - S23). Significant spectral overlaps thus preclude more elaborate interpretations for $[\mathbf{Z n}, \mathbf{N d}],[\mathbf{Z n}, \mathbf{Z n}]$, and $[\mathbf{Z n}, \mathbf{Y}]$.

\section{Single Crystal X-ray Diffraction Studies}

$X$-ray diffraction (XRD) analysis of single crystals of the bimetallic complexes containing $\mathrm{Na}^{+}, \mathrm{Ca}^{2+}, \mathrm{Zn}^{2+}, \mathrm{Nd}^{3+}$, and $\mathrm{Y}^{3+}$ confirm assembly of the desired $\mathrm{Zn}^{\prime \prime}\left(\mu_{2}-\mathrm{O}_{\mathrm{Ar}}\right)_{2} \mathrm{M}$ cores in all cases. Our structures complement a wealth of prior data (over 500 examples) available in the Cambridge Structural Database ${ }^{24}$ for zinc(II) complexes supported by a variety of salen and salophen derivatives. Among these, only a limited number contain more than one unique metal-binding site. There are only two examples of heterobimetallic complexes built on heteroditopic and macrocyclic ligands. ${ }^{25}$ The remaining related bi- or multi-metallic compounds are, for example, homobimetallic and based on homoditopic ligands, ${ }^{26}$ homobimetallic but lacking macrocyclic stabilization, ${ }^{27}$ dimerized structures based on monomeric metal building blocks, ${ }^{28}$ or macrocyclic and based upon homoditopic ligands. 29 There are also numerous examples ${ }^{30}$ of nonmacrocyclic, heterobimetallic complexes conceptually related to the early work ${ }^{20}$ of Milburn, Truter, and Vickery; the solutionphase persistence of these remains a topic of interest to us considering their lack of macrocyclic stabilization.

The zinc(II) ion bound in the tetradentate Schiff base site of the salophen moiety is coordinated by five ligands in all cases, with four coordination sites taken up by the Schiff base ligand. The structural parameters (see Table 1 for details) reveal the coordination number (C.N.) of the sodium ion in [Zn,Na] to be 7 , and that of the calcium ion in $[\mathrm{Zn}, \mathrm{Ca}]$ to be 8 , while $[\mathrm{Zn}, \mathrm{Nd}]$ and $[Z n, Y]$ have $\mathrm{Nd}^{3+}$ and $\mathrm{Y}^{3+}$ with C.N. = 9. Notably, however, we found that the $\mathrm{Zn}^{2+}$ ion located in the crown-ether-like site of $[\mathbf{Z n}, \mathbf{Z n}]$ displays a tetrahedral geometry with C.N. $=4$ in two different structures obtained from the crystallization conditions (vide infra), consistent with its smaller ionic radius.

Regarding the structure of [ $\mathbf{Z n}, \mathbf{N a}]$, the dashed lines in Figure 1 indicate a noncovalent stacking interaction between the sodium cations and the phenylene rings of the salophen units in each heterobimetallic complex that is present in the asymmetric unit. Based on the rather long $\mathrm{Na} 1 \mathrm{~A} \cdots \mathrm{C} 24 \mathrm{~B}$ and $\mathrm{Na} 1 \mathrm{~B} \cdots \mathrm{C} 24 \mathrm{~A}$ distances (3.036(4) and 3.019(4) $\AA$, respectively), as well as the lack of any differentiation of the $\mathrm{C}-\mathrm{C}$ bonds in the phenylene rings, we can confidently assign this feature as a purely non-covalent stacking phenomenon.

Crystals of $[\mathbf{Z n}, \mathbf{N a}]$ were only obtained by vapor diffusion of ether into dimethylformamide (DMF). As a result, three O-bound DMF molecules are present in the structure (Figure 1). Similarly, crystals of $[\mathbf{Z n}, \mathbf{C a}]$ were only obtained by vapor diffusion of ether into a methanol solution of the compound, leading to one $\mathrm{MeOH}$ bound each to the $\mathrm{Zn}$ and $\mathrm{Ca}$ centers in the complex (Figure 2). $\mathrm{H}$-bonding between these bound $\mathrm{MeOH}$ molecules and an outersphere triflate anion is apparent in the structure.

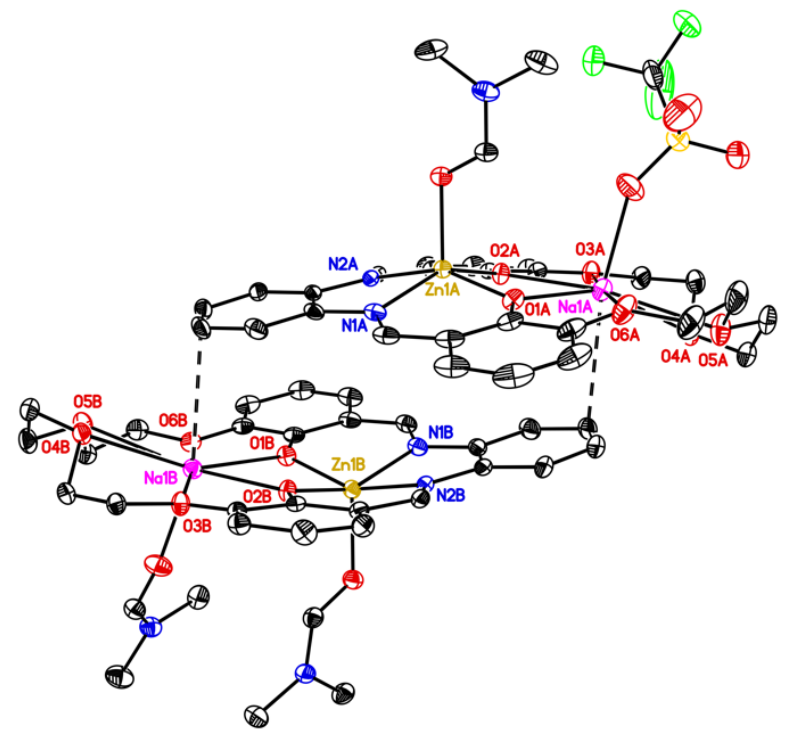

Figure 1. Solid-state structure (from XRD) of [Zn,Na]. All H-atoms, disorder in the triflate bound to $\mathrm{Na} 1 \mathrm{~A}$, and one outer-sphere triflate are omitted for clarity. Displacement ellipsoids are shown at the $20 \%$ probability level. Dashed lines indicate non-covalent stacking interactions between the sodium cations and the phenylene rings of the adjacent heterobimetallic complex (see main text for description).

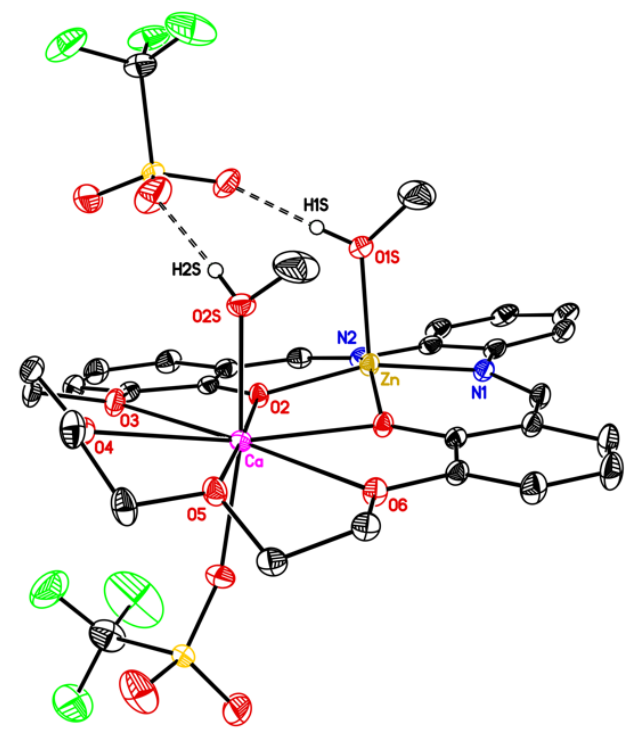

Figure 2. Solid-state structure (from XRD) of [Zn,Ca]. H-atoms except those covalently bonded to $\mathrm{O} 1 \mathrm{~S}$ and $\mathrm{O} 2 \mathrm{~S}$ that are involved in intermolecular $\mathrm{O}-\mathrm{H} \cdots \mathrm{O}$ hydrogen-bonds are omitted for clarity. Displacement ellipsoids are shown at the $20 \%$ probability level. 
Table 1. Comparison of Lewis acidities (aqua ion $\mathrm{pK}$ a values) with structural parameters from X-ray diffraction studies for the complexes [Zn,M].

\begin{tabular}{|c|c|c|c|c|c|c|}
\hline & {$[\mathrm{Zn}, \mathrm{Na}]$} & {$[\mathrm{Zn}, \mathrm{Ca}]$} & {$[\mathrm{Zn}, \mathrm{Nd}]$} & {$[\mathrm{Zn}, \mathrm{Y}]$} & {$\left[\mathrm{Zn}, \mathrm{Zn}-\mathrm{OH}_{2}\right]$} & {$\left[(\mathrm{Zn}, \mathrm{Zn})_{2}-\mu-\mathrm{OH}\right]$} \\
\hline $\mathrm{p} K_{\mathrm{a}}$ of $\left[\mathrm{M}\left(\mathrm{H}_{2} \mathrm{O}\right)_{\mathrm{m}}\right]^{\mathrm{n}+}$ & 14.8 & 12.6 & 8.4 & 8.3 & 9.0 & 9.0 \\
\hline Ionic Radius $(\hat{A})$ of $M^{[a]}$ & 1.12 & 1.12 & 1.16 & 1.08 & 0.6 & 0.6 \\
\hline Coord. Number of $M$ & 7 & 8 & 9 & 9 & 4 & 4 \\
\hline$Z n \bullet \cdots M(\AA)$ & $3.421(1), 3.464(1)$ & $3.476(1)$ & $3.478(1)$ & $3.384(1)$ & $3.070(1)$ & $3.055(1), 3.091(1)$ \\
\hline $\boldsymbol{\omega}_{\text {crown }}{ }^{[b]}$ & $0.246,0.242$ & 0.126 & 0.386 & 0.665 & 0.256 & $0.109,0.298$ \\
\hline$\omega_{\text {salophen }}{ }^{[c]}$ & $0.044,0.021$ & 0.063 & 0.013 & 0.022 & 0.011 & $0.100,0.021$ \\
\hline $\boldsymbol{\psi}_{\mathrm{Zn}}(\AA)^{[\mathrm{d}]}$ & $0.474,0.459$ & 0.401 & 0.534 & 0.389 & 0.594 & $0.501,0.544$ \\
\hline
\end{tabular}

The structures of $[\mathbf{Z n}, \mathbf{N d}]$ and $[\mathbf{Z n}, \mathbf{Y}]$ (see Figure 3) represent a notable pair, since $\mathrm{Nd}^{3+}$ and $\mathrm{Y}^{3+}$ have the same charge $(+3)$ and coordination number (9) but different ionic radii (1.16 $\AA$ vs. 1.08 A).$^{31}$ In these structures, $\mathrm{Nd}^{3+}$ and $\mathrm{Y}^{3+}$ are both located in the crown-ether-like site, and both ions are coordinated by three $\mathrm{K}^{1}$ triflate molecules. On the other hand, the structure of $[\mathbf{Z n}, \mathbf{Y}]$ reveals a very different orientation of the crown ether ring relative to the plane of the salophen moiety; in $[\mathrm{Zn}, \mathrm{Y}]$, the structure is folded in order to allow one triflate bound to $\mathrm{Y}^{3+}$ to serve as a bridging ligand with $\mathrm{Zn}^{2+}$. As a result, the $\mathrm{Zn} \cdots \mathrm{M}$ distance in $[\mathrm{Zn}, \mathrm{Y}]$ is shorter by $0.09 \AA$. Notably, however, this bridging interaction does not "pull" the zinc ion further out of the plane of the salophen ligand, as the distance ( $\psi_{\mathrm{zn}}$ value, see Table 1$)$ of the zinc center from the centroid of the plane defined by $\mathrm{O} 1, \mathrm{O} 2$, $\mathrm{N} 1$ and $\mathrm{N} 2$ is significantly longer for $[\mathbf{Z n}, \mathbf{N d}]$ than $[\mathbf{Z n}, \mathrm{Y}]$. On the other hand, the significant distortion of the macrocyclic structure upon coordination of $\mathrm{Y}^{3+}$ may contribute to the smaller $\psi \mathrm{zn}$ value for $[\mathbf{Z n}, \mathbf{Y}]$. In our prior work with nickel complexes based upon the same macrocyclic ligand studied here, we found that the analogous $[\mathrm{Ni}, \mathrm{Y}]$ complex displayed a weak interaction between a triflate ligand bound to $\mathrm{Y}^{3+}$ and the essentially square planar $\mathrm{Ni}(\mathrm{II})$ center at $2.786 \AA$ (cf. $[\mathrm{Zn}, \mathrm{Y}]$ at $2.094(3) \AA$ ). ${ }^{11}$ This finding suggests that the $\mathrm{Y}^{3+}$ ion with its large charge to radius ratio tends to uniquely engender $M \cdots Y$ bridging interactions in Reinhoudttype macrocyclic ligands, and confirms that $\mathrm{Zn}$ (II) prefers a fivecoordinate geometry in comparison with square-planar $\mathrm{Ni}(\mathrm{II})$.

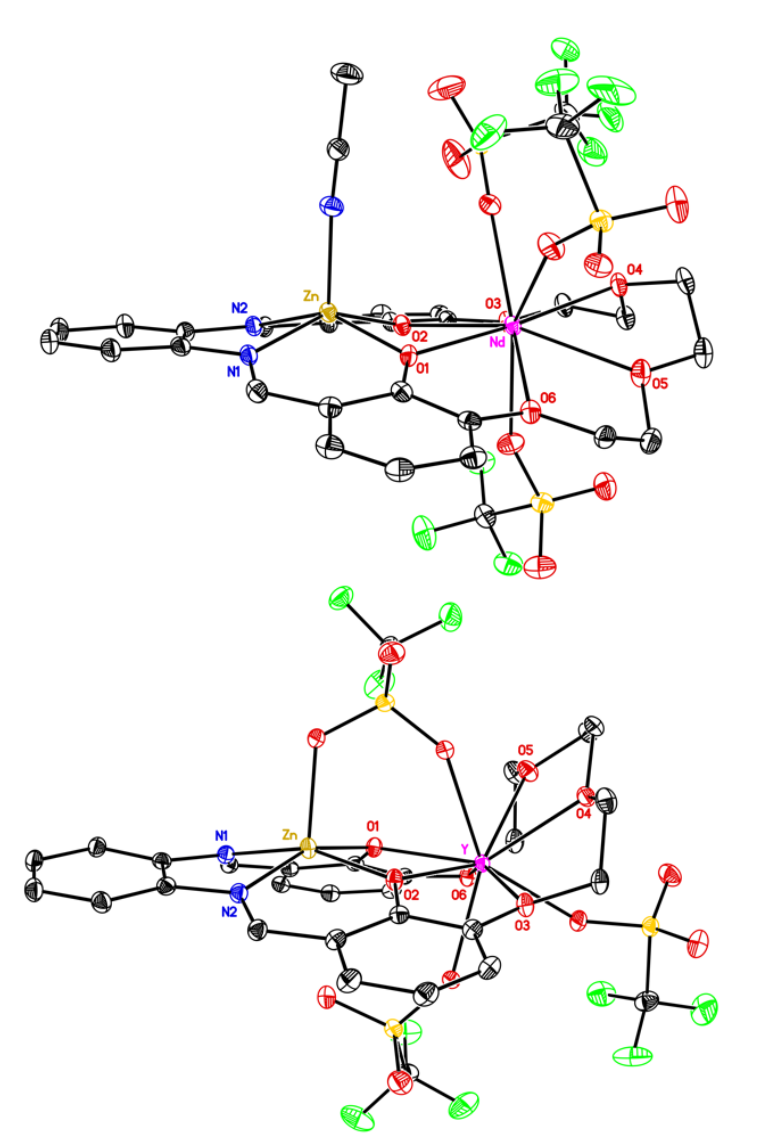

Figure 3. (a) Upper structure: solid-state structure (from XRD) of [Zn,Nd]. All $\mathrm{H}$-atoms, the disorder of one triflate counter-anion and one outer-sphere acetonitrile solvent molecule are omitted for clarity. Displacement ellipsoids are shown at the $20 \%$ probability level. (b) Lower structure: solid-state structure (from XRD) of [Zn,Y]. All H-atoms are omitted for clarity. Displacement ellipsoids are shown at the $20 \%$ probability level. 
Although [ $\mathbf{Z n , Z n ] ~ c o u l d ~ b e ~ r e l i a b l y ~ i s o l a t e d ~ i n ~ a n h y d r o u s ~ f o r m ~ ( o n ~}$ the basis of ${ }^{1} \mathrm{H}$ NMR spectroscopy, see SI Figure S15) and handled without noticeable decomposition in our dry inertatmosphere gloveboxes, single crystals and elemental analysis data (see Experimental Section) were obtained that show uptake of water into the structure, as shown in Figures 4 and 5 . These structures, labeled as $\left[\mathbf{Z n}, \mathbf{Z n}-\mathrm{OH}_{2}\right]$ and $\left.\left[(\mathbf{Z n}, \mathbf{Z n})_{2}-\mu-\mathrm{OH}\right]\right)$, support the hypothesis that the high charge to ionic radius ratio of $\mathrm{Zn}^{2+}$ contributes to an especially hygroscopic nature of $[\mathbf{Z n}, \mathbf{Z n}]$. The structure of $\left[\mathbf{Z n}, \mathbf{Z n}-\mathrm{OH}_{2}\right]$ shows that $[\mathbf{Z n}, \mathbf{Z n}]$ prefers to take up water at the zinc center ligated by the $\mathrm{K}^{2}$-macrocyclic framework; this preference is likely engendered by the nearby free ether moiety, which can engage in intramolecular hydrogen bonding with one $\mathrm{O}-\mathrm{H}$ on the $\mathrm{Zn}$-bound water molecule. Examination of the structure of $\left[(\mathbf{Z n}, \mathbf{Z n})_{2}-\mu-O H\right]$ reveals a similar situation, wherein the $\mu_{2}$-hydroxo moiety which bridges between two fourcoordinate zinc centers can engage in $\mathrm{H}$-bonding with one ether functionality. [(Zn, $\left.\mathbf{Z n})_{2}-\mu-O H\right]$ represents a dimerized form of [Zn, $\mathbf{Z n}-\mathbf{O H}_{2}$ ]; the dimer could reasonably form by deprotonation of the water in $\left[\mathbf{Z n}, \mathbf{Z n}-\mathbf{O H}_{2}\right]$ (acidified by interaction with the Lewis acidic $\mathrm{Zn}$ center) followed by dimerization promoted by the availability of a bridging ligand. Stacking interactions between the more planar salophen groups could promote this dimerization and effective crystal packing as well.

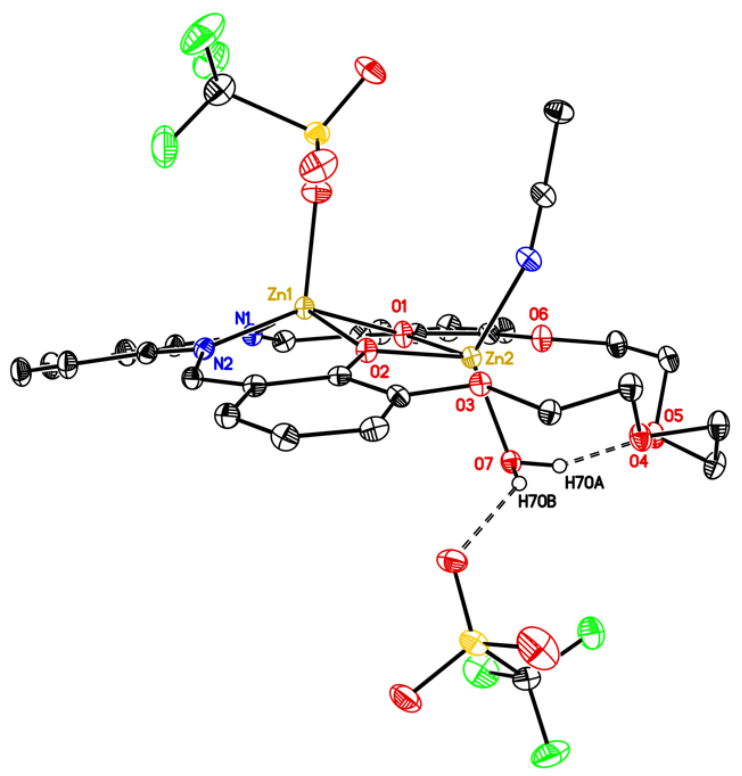

Figure 4. Solid-state structure (from XRD) of [ $\left.\mathrm{Zn}, \mathrm{Zn}-\mathrm{OH}_{2}\right]$. H-atoms except those covalently bonded to $\mathrm{O} 7$ and involved in intermolecular and intramolecular $\mathrm{O}-\mathrm{H} \cdots \mathrm{O}$ hydrogen bonds are omitted for clarity. Displacement ellipsoids are shown at the $20 \%$ probability level.

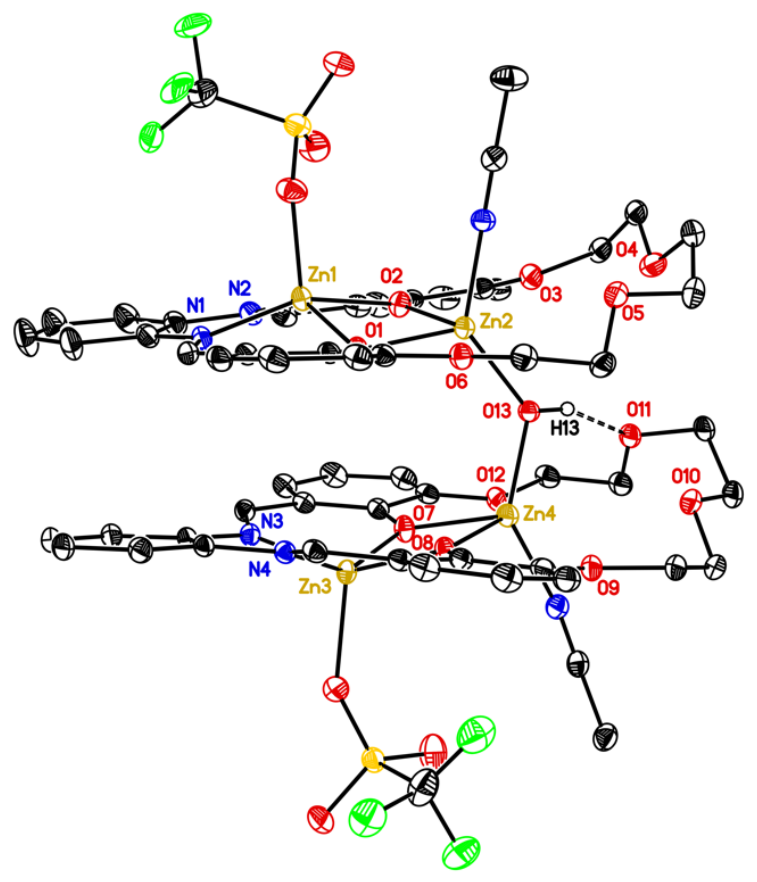

Figure 5. Solid-state structure (from XRD) of [(Zn, Zn $\left.)_{2}-\mu-O H\right]$. $\mathrm{H}$-atoms except those covalently bonded to $\mathrm{O} 13$, one disordered $\mathrm{CH}_{3} \mathrm{CN}$ solvent molecule and one outer-sphere triflate counter-anion are omitted for clarity. Displacement ellipsoids are shown at the $20 \%$ probability level.

With this comprehensive set of crystallographic data in hand, a number of trends in the influences of the secondary Lewis acidic metals on the structure of the zinc complexes can be observed. First, the $\omega_{\text {crown }}$ parameters (see Table 1 for values and definition of this parameter) for the complexes show that the macrocyclic structure is most significantly deformed upon coordination of the trivalent Lewis acidic metals ( $\omega_{\text {crown }}=0.386$ and 0.665 for $[\mathbf{Z n}, \mathbf{N d}]$ and $[\mathbf{Z n}, \mathbf{Y}]$, respectively). This is likely driven by the preference of these ions for a high coordination number of 9 . The $\mathrm{Zn} \cdots \cdot \mathrm{M}$ distances are generally dependent upon the ionic radius of the incorporated secondary metals, as exemplified by the structures of $\left[\mathrm{Zn}, \mathrm{Zn}-\mathrm{OH}_{2}\right]$ and $\left[(\mathrm{Zn}, \mathrm{Zn})_{2}-\boldsymbol{\mu}-\mathrm{OH}\right]$, which show the shortest intermetallic distances of ca. $3.07 \AA$. Second, the rigidity of the salophen-based macrocyclic ligand framework, buttressed by the conjugated nature of the phenylene diimine bridging unit, is clear in the modest values of $\omega_{\text {salophen }}$ across the series of complexes. This rigidity is further evident in the narrow range of values associated with the $01 \cdots 02$ distances in the bimetallic zinc complexes; these values contrast with the much wider range of values that we observed in our series of heterobimetallic uranyl complexes. ${ }^{10}$ As the uranyl complexes are based upon the much more flexible "salben" macrocyclic framework, we conclude that ligand rigidity is an important determinant of the structural characteristics of the heterobimetallic complexes in our series. An appealing area for future synthetic efforts could include comparative studies of bimetallic complexes based upon conjugated and non-conjugated ligand derivatives, although we anticipate that more flexible ligand frameworks might be more prone to promotion of speciation of the multiple metal centers involved in such compounds. 


\section{Electrochemical Studies}

With the observation of the apparent stability of the bimetallic zinc complexes in acetonitrile solution, we next moved to investigate their reductive electrochemical properties with cyclic voltammetry (CV; see Figure 6). To the best of our knowledge, electrochemical data has not been previously available for macrocyclic bimetallic complexes containing zinc; this could be attributable to the poor stability of complexes containing zinc with other metals.

To begin, electrochemical data for the monometallic complex [ $\mathrm{Zn}]$ revealed a reduction process as a minor shoulder near the limit of our range of accessible potentials (see SI, Figures S25 - S28). This observation is consistent with prior work on Schiff-base-type complexes of zinc, ${ }^{32}$ and also with the recognized propensity of zinc(II) to be "redox inactive" under typically accessible potential ranges. This characteristic is fundamentally related to its rather negative standard reduction potential $\left(E^{\circ}\left(\mathrm{Zn}^{2+/ 0}\right)=-0.76 \mathrm{~V}\right.$ vs. the normal hydrogen electrode, $\mathrm{NHE})\left(\mathrm{cf} . E^{\circ}\left(\mathrm{Ni}^{2+10}\right)=-0.26 \mathrm{~V}\right.$ vs. $\mathrm{NHE}){ }^{33}$ In acetonitrile solution, we have recently confirmed a quite negative effective potential for reduction of $\mathrm{Zn}^{2+}$ to $\mathrm{Zn}^{0}$ with electrochemical quartz crystal microbalance (EQCM) studies of its hexakis(acetonitrile) complex, which show that free zinc ions ligated solely by acetonitrile ligands do not undergo reduction on pyrolytic graphite or gold electrodes until ca. $-1.5 \mathrm{~V}$ versus ferrocenium/ferrocene (denoted hereafter as $\mathrm{Fc}^{+/ 0}$ ). ${ }^{34}$ In any case, our studies here (i) confirm that $[\mathbf{Z n}]$ is redox inactive up until the rather negative potential of ca. $-2.5 \mathrm{~V}$ vs. $\mathrm{Fc}^{+/ 0}$ and that (ii) solutions containing $[\mathrm{Zn}]$ do not release free $\mathrm{Zn}^{2+}$ ions.

On the other hand, [ $\mathbf{Z n}, \mathbf{N a}$ ] undergoes a chemically and electrochemically irreversible reduction with a readily accessible cathodic peak reduction potential $\left(E_{\mathrm{p}, \mathrm{c}}\right)$ at $-1.8 \mathrm{~V} \mathrm{vs}$. $\mathrm{Fc}^{+/ 0}$ (see Figure 6). This indicates that incorporation of $\mathrm{Na}^{+}$into [Zn] enables reduction of the complex at a significantly more positive value that is within our accessible range, making the compound quite suitable for detailed electroanalytical investigations. Hence, incorporation of Lewis acids promotes the reduction of our zinc complexes.

As the cathodic peak current is linearly dependent upon scan rate (see SI for data), [Zn,Na] can be confirmed as freely diffusing at the electrode surface. On the other hand, no return anodic waves are apparent at scan rates up to $500 \mathrm{mV} / \mathrm{s}$ that produce reliable data with our equipment; we anticipate that the reduced form of [Zn,Na] undergoes a rapid chemical reaction that depletes the material from the diffusion-reaction layer, precluding observation of a return wave. This profile corresponds to an EC-type mechanism, ${ }^{35}$ as the initial electrochemical reduction is followed by a chemical reaction. In the analogous data for [ $\mathbf{Z n}]$, the involvement of EC-type reactivity is further implicated by the presence of a minor re-oxidation wave with a potential shifted positive by ca. $1.5 \mathrm{~V}$ (see SI, Figure S26).

As zinc can be reliably considered a redox-inactive metal and salophen-type ligands are known to be redox-active themselves under certain conditions, we conclude that the reduction measured for $[\mathrm{Zn}, \mathrm{Na}]$ is ligand centered. This is in accord with the chemically irreversible nature of the data for this compound, in that Vianello and co-workers have previously demonstrated that ligand-centered reduction of salophen-like compounds results in Cimine-localized electron density which promotes intermolecular
C- $\mathrm{C}$ coupling reactions and formation of secondary products from the nascent reduced material formed at the electrode surface. ${ }^{36}$ Similar reactivity has also been observed by Mazzanti and coworkers in recent work with cobalt complexes. ${ }^{37}$ In the case of our macrocyclic salophen ligand system, we conclude that the Lewis acidic nature of $\mathrm{Zn}^{2+}$ in concert with added $\mathrm{Na}^{+}$exerts a suitable influence on the ligand framework to enable it to undergo reduction in $[\mathrm{Zn}, \mathrm{Na}]$.

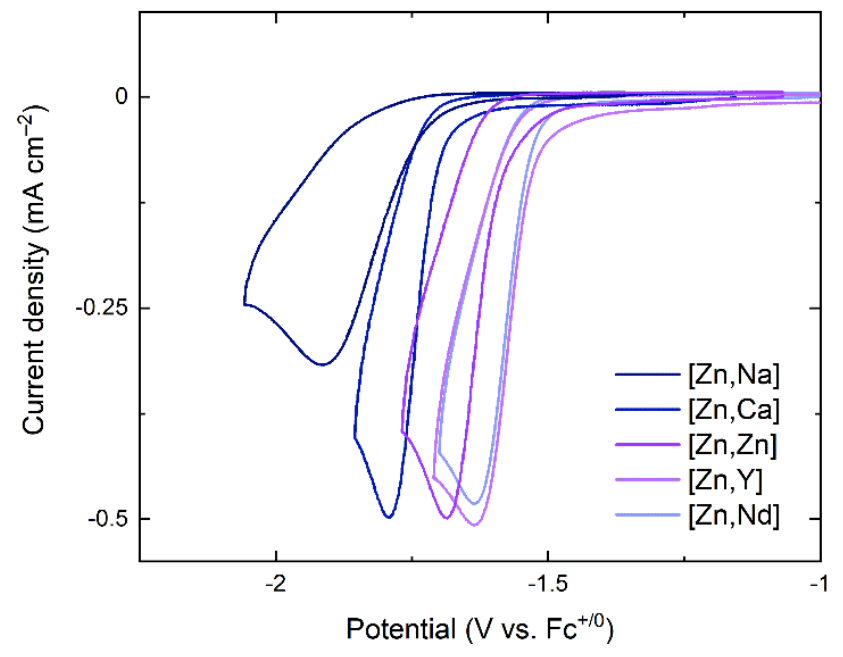

Figure 6. Cyclic voltammetry data for the complexes [Zn,M]. Conditions: $0.1 \mathrm{M}$

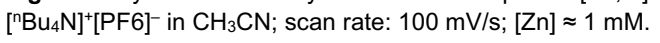

The potentials for reduction of $[\mathbf{Z n}, \mathbf{Z n}],[\mathbf{Z n}, \mathbf{N d}]$, and $[\mathbf{Z n}, \mathbf{Y}]$ are shifted further to more positive values (see Table 2), consistent with retention of the coordinated secondary metal ions in the crown-ether-like site resulting in the noted shifts. Scan-rate dependent studies reveal that all three of the compounds with stronger di- and tri-valent Lewis acids incorporated are freely diffusing (see SI, Figures S37, S40, and S43). The noted positive shift of the reduction potentials is reminiscent of phenomena observed in other heterobimetallic systems, albeit ones containing at least one redox-active metal. Of particular relevance, in our previous work with heterobimetallic [Ni,M] complexes, ${ }^{11}$ we tabulated cathodic peak reduction potentials to quantify the influence of redox-inactive Lewis acidic metals on the $\mathrm{Ni}^{\prime \prime} / \mathrm{Ni}^{1}$ redox manifold. Taking the same strategy here for the $[\mathrm{Zn}, \mathrm{M}]$ series, plotting $E_{\mathrm{p}, \mathrm{c}}$ for the reduction processes shown in Figure 6 versus the $\mathrm{p} K_{\mathrm{a}}$ values of the corresponding secondary redoxinactive metal aqua complexes reveals a clear dependence. In particular, least squares fitting of the data to a linear trend reveals a relationship with an absolute value of $41 \mathrm{mV} / \mathrm{p} K_{\mathrm{a}}$ (see Figure 7). Thus, there is a clear and uniform trend of modulated potentials for ligand-centered reduction upon incorporation of secondary Lewis acidic metals into macrocyclic zinc complexes. 
Table 2. Electrochemical Characteristics of the Bimetallic Zinc Complexes.

\begin{tabular}{lllll}
\hline & $\begin{array}{l}\mathrm{p} K_{\mathrm{a}} \text { of } \\
{\left[\mathrm{M}\left(\mathrm{H}_{2} \mathrm{O}\right)_{\mathrm{m}}\right]^{\mathrm{n}}}\end{array}$ & $E_{\mathrm{p}, \mathrm{c}}(\mathrm{V})^{[\mathrm{a}]}$ & $E_{\mathrm{p} / 2}(\mathrm{~V})^{[\mathrm{b}]}$ & $\lambda(\mathrm{eV})^{[\mathrm{b}]}$ \\
\hline$[\mathrm{Zn}, \mathrm{Na}]$ & 14.8 & -1.92 & -1.81 & 0.74 \\
{$[\mathrm{Zn}, \mathrm{Ca}]$} & 12.6 & -1.79 & -1.74 & 0.16 \\
{$[\mathrm{Zn}, \mathrm{Zn}]$} & 9.0 & -1.69 & -1.63 & 0.21 \\
{$[\mathrm{Zn}, \mathrm{Nd}]$} & 8.4 & -1.64 & -1.57 & 0.24 \\
{$[\mathrm{Zn}, \mathrm{Y}]$} & 8.3 & -1.64 & -1.57 & 0.28 \\
\hline
\end{tabular}

[a] Measured at $100 \mathrm{mV} / \mathrm{s}$. [b] Average of measurements at various scan rates (see Supporting Information for details).

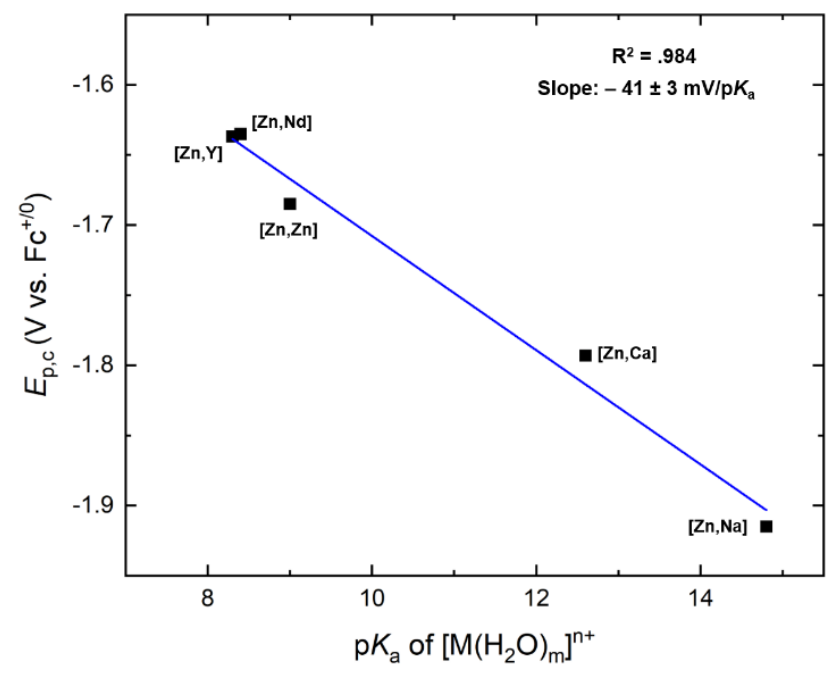

Figure 7. Plot of $E_{p, c}$ for the bimetallic zinc complexes vs. $p K_{a}$ of $\left[\mathrm{M}\left(\mathrm{H}_{2} \mathrm{O}\right)_{\mathrm{m}}\right]^{\mathrm{nt}}$

In addition to the uniform trend in $E_{\mathrm{p}, \mathrm{c}}$ observed for these bimetallic compounds, the more Lewis acidic metals also effect the shape of the reductive waves shown in Figure 6, wherein the voltammogram for $[\mathbf{Z n}, \mathbf{N a}]$ is rather broad in comparison to the sharper waves for the other complexes. This implies that the derivatives containing stronger Lewis acids undergo faster heterogeneous electron transfer. ${ }^{38}$ However, this estimation is only qualitative, since the customary calculation of the standard heterogeneous electron transfer rate $\left(k^{\circ}\right)$ cannot be completed here due to the lack of a paired re-oxidation wave for the series [Zn,M], a feature that is required for the calculation of $k^{\circ}$ with the method of Nicholson. ${ }^{39}$ To quantitatively investigate this feature here, the reorganization energies associated with reductive electron transfer $(\lambda)$ to all the bimetallic complexes were calculated instead. Our calculation is based upon Savéant and Costentin's powerful approach, ${ }^{35}$ wherein the broadness of the voltammetric waves is quantified through comparison of $E_{\mathrm{p}, \mathrm{c}}$ and $E_{\mathrm{p} / 2}$ (where $E_{\mathrm{p} / 2}$ is the voltammetric potential at which the half-max current is flowing). With this value, the transfer coefficient and free energy of activation can be estimated, leading to the quantification of the reorganization energy. ${ }^{40}$ (See SI for details on calculations.) As expected, the $\lambda$ values for the derivatives containing di- and trivalent Lewis acids (spanning $0.16-0.28 \mathrm{eV}$ ) are all significantly lower than the value for [ $\mathrm{Zn}, \mathrm{Na}]$ of $0.73 \mathrm{eV}$ (see Figure 8). Thus, the activation free energy for electron transfer to [Zn,Na] is significantly greater than for the other compounds in this series. Additionally, when the $\lambda$ values are plotted as a function of the $\mathrm{p} K_{\mathrm{a}}$ values associated with the incorporated secondary metals, a nonmonotonic relationship emerges wherein the reorganization energy is smallest for [ $\mathbf{Z n}, \mathbf{C a}$ ] and increases modestly up through $[\mathrm{Zn}, \mathrm{Y}]$ and most markedly for $[\mathrm{Zn}, \mathrm{Na}]$.

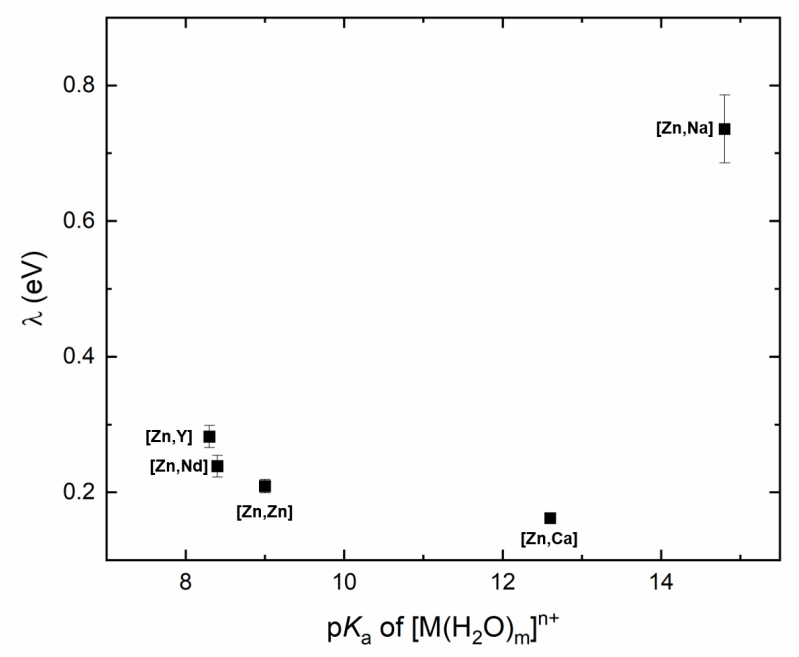

Figure 8. Plot of $\lambda$ for the bimetallic zinc complexes vs. $p K_{a}$ of $\left[\mathrm{M}\left(\mathrm{H}_{2} \mathrm{O}\right)_{\mathrm{m}}\right]^{\mathrm{n}}$.

\section{Discussion}

In our previous work with heterobimetallic nickel and uranyl complexes, ${ }^{10,11}$ we tabulated cathodic peak reduction potentials $\left(E_{\mathrm{p}, \mathrm{c}}\right)$ in order to quantify the influence of redox-inactive Lewis acids on the $\mathrm{Ni}^{\mathrm{lll} /}$ and $\mathrm{U}^{\mathrm{VIV}}$ reduction processes. We took the same strategy here in order to examine new data for bimetallic compounds containing only zinc(II) and other secondary redoxinactive metal ions. In particular, our prior work with complexes of the form $[\mathrm{Ni}, \mathrm{M}]$ as well as the present work with the $[\mathrm{Zn}, \mathrm{M}]$ series were both based upon the same heteroditopic salophen-based macrocyclic ligand developed by Reinhoudt. ${ }^{18}$ Here, plotting $E_{\mathrm{p}, \mathrm{c}}$ vs. the Lewis acid $p K_{a}$ values ${ }^{16}$ reveals a slope with an absolute value of $41 \pm 3 \mathrm{mV} / \mathrm{pK}$ a. This is significantly smaller than the trend observed for the [Ni,M] series of $70 \pm 12 \mathrm{mV} / \mathrm{pK}$ a. It is also smaller than the trend of $61 \pm 9 \mathrm{mV} / \mathrm{p} K_{\mathrm{a}}$ observed for our $\left[\mathrm{UO}_{2}, \mathrm{M}\right]$ series, identical within the calculated error to that of the $[\mathrm{Ni}, \mathrm{M}]$ series. Consequently, this estimate of the influence of the secondary Lewis acidic metals on the $[\mathrm{Zn}, \mathrm{M}]$ series confirms that the nature of the redox process occurring with these compounds is distinctive. We anticipate that this is due to the use of solely redoxinactive metals in the $[\mathrm{Zn}, \mathrm{M}]$ series, and that the trend of $41 \pm 3$ $\mathrm{mV} / \mathrm{p} K_{\mathrm{a}}$ is smaller than the other cases for this reason.

Similar to the systems with redox-active metals, the trivalent Lewis acidic metals result in the most pronounced shifts in $E_{\mathrm{p}, \mathrm{c}}$. However, the change in $E_{\mathrm{p}, \mathrm{c}}$ that is achieved over the full range investigated here $(280 \mathrm{mV})$ is significantly smaller than that achieved with our other systems. We anticipate that this difference is ascribable to the localization of the orbitals undergoing reduction in the complexes in each case. In the case of the $\mathrm{Ni}$ and $\mathrm{U}$ complexes, metal-centered orbitals take up the 
transferred electrons, a situation and assignment supported by spectroelectrochemical results. ${ }^{10}$ Here, we anticipate that ligandcentered orbitals in the highly conjugated salophen moiety take up the transferred electron. These orbitals are spatially separated by a greater distance from the incorporated secondary redoxinactive Lewis acids. Thus, their influence on the chemistry and electrochemistry of the conjugated system can be reasonably imagined to be more modest than in other cases. This theory is consistent with recent notable discussions from the literature regarding electrostatic effects on catalysis. ${ }^{23,41}$

In addition to the uniform trend in peak cathodic reduction potentials, it is notable that the stronger di- and tri-valent Lewis acids investigated here engender faster electron transfer to the $[\mathrm{Zn}, \mathrm{M}]$ complexes in comparison to [Zn,Na]. To investigate this phenomenon with quantitative methods, the reorganization energies (associated with the reduction processes were calculated and compared. As expected the value of $\lambda$ for [Zn, Na] is significantly greater $(0.73 \mathrm{eV})$ than for the other bimetallic complexes containing stronger Lewis acids $(0.16-0.28 \mathrm{eV})$. The wide total span of values surprised us both because the compounds in our series are based upon a common supporting ligand that is macrocyclic in nature as well as because the trend is quite different from what we previously observed with our $\left[\mathrm{UO}_{2}, \mathrm{M}\right]$ heterobimetallic complexes. ${ }^{10}$ In this work, a monotonic trend of increasing reorganization upon reduction was measured, giving rise to deceleration of electron transfer with strong Lewis acids. Similar trends are apparent in the data for our [Ni,M] series,$^{11}$ although further work remains in quantifying the trends with those compounds. In the present work, a non-monotonic trend was measured where the weakest Lewis acid studied $\left(\mathrm{Na}^{+}\right)$ gives rise to the largest reorganization energy in the series. Thus, the kinetic behavior of the $[\mathrm{Zn}, \mathrm{M}]$ series also fundamentally differs from our prior work with the redox-active metals. Because delocalized, ligand-centered orbitals take up the transferred electrons in the $[\mathrm{Zn}, \mathrm{M}]$ series, we hypothesize that the diminished reorganization energy associated with the bimetallic species incorporating stronger Lewis acids is associated with macrocyclic rigidification, wherein the structures of the oxidized and reduced forms of the complexes differ less when the electron-poor and highly charged Lewis acids are present. In such a model, the significantly shortened $\mathrm{O} 1 \cdots \mathrm{O} 2$ distances for [Zn,Ca], [Zn,Nd], $[\mathbf{Z n}, \mathrm{Y}]$, and both crystallized forms of $[\mathbf{Z n}, \mathbf{Z n}]$ in comparison to [Zn,Na] (by $0.08,0.16,0.10,0.18$, and $0.14 \AA$, respectively) could be taken as indication of tight Lewis acid binding and a drawing together of these macrocyclic structures upon coordination of the redox-inactive cations. This in turn could promote diminished reorganization of these complexes following initial electron transfer.

Taken together, the quantified trends in these data offer metrics that help distinguish metal- versus ligand-centered reduction of heterobimetallic complexes. The trend in $E_{\mathrm{p}, \mathrm{c}}$ values as a function of the Lewis acid $p K_{a}$ values is especially instructive, and may provide a metric for understanding the distance dependence of Lewis acid tuning effects. This possible opportunity is bolstered by our prior finding that $\mathrm{Ni}$-based tuning was slightly more sensitive that $\mathrm{U}$-based tuning, although our ongoing work remains focused on development of a more detailed understanding of how $3 d$ vs. $5 f / 6 d$ orbitals contribute to covalency and coupling phenomena in heterobimetallic complexes. The non-monotonic relationship between reorganization energies $\lambda$ and Lewis acidity requires further investigations, in our view, before drawing general conclusions. In part, we anticipate that the chemical reactivity that may follow the first electron transfer event could be quite diverse, and dependent upon the identity of both the metal and ligand. For example, uranyl complexes may undergo oxofunctionalization or O-M bond formation promoted by Lewis acids, contributing to greater structural differences between oxidized and reduced forms. ${ }^{12}$ In the case of derivatives incorporating only redox-inactive metals, such reactions are not accessible, although organic reactivity promoted by the multiple Lewis acids is implicated by our data.

The work described here confirms that multiple, different Lewis acidic metals can simultaneously influence organic compounds' electrochemistry and reactivity, for example by promoting the reduction of the salophen-based macrocyclic ligand studied here. Our results, taken together, show that such effects can be quantified and understood through electrochemical methods in concert with structural analysis. Thus, the future remains bright for further developments in heterobimetallic chemistry, enabled by the remarkable tools of molecular electrochemistry as elaborated by Jean-Michel Savéant throughout his truly distinguished career.

\section{Conclusion}

Redox-inactive Lewis acidic metals have been shown to be effective in uniformly tuning the electronic properties and reduction potential of macrocyclic complexes of the zinc(II) ion. These findings have been enabled here by preparation of the first structurally characterized series of bimetallic macrocyclic $\mathrm{Zn}$ (II) complexes. Similar to the case of first-row transition metal and uranyl complexes, we find a shift in reduction potential that linearly depends upon the Lewis acidity of the incorporated secondary metal ions, as judged by the $\mathrm{p} K_{\mathrm{a}}$ values of the corresponding metal aqua ions. Electrochemical studies show a non-monotonic relationship between the reorganization energy associated with electron transfer and Lewis acidity, suggesting a role for individual metal ions' chemical reactivity patterns in influence electron transfer kinetics. These findings advance understanding of the scope of influences that redox-inactive metal cations can have on the electrochemical properties of redox-active compounds, furthering the foundation of knowledge for new and perhaps practical applications of heteromultimetallic complexes.

\section{Experimental Section}

\section{General Considerations}

Unless otherwise noted, all experiments were carried out under inert atmosphere; either in a dry, $\mathrm{N}_{2}$-filled glovebox (Vacuum Atmospheres Co., Hawthorne, CA) or under $\mathrm{N}_{2}$ using standard Schlenk techniques. All solvents were commercial grade and dried using activated alumina on a PPT Glass Contour (Nashua, NH) solvent purification system prior to use. Dried solvents were stored over molecular sieves in a dry, $\mathrm{N}_{2}$-filled glovebox. All chemicals were purchased from commercial suppliers and dried in vacuo on a Schlenk line. Deuterated solvents were obtained from Cambridge Isotope Laboratories and dried using $4 \AA$ molecular sieves and vacuum transferred prior to use. NMR spectra were collected on either a $400 \mathrm{MHz}$ or $500 \mathrm{MHz}$ Bruker instruments and referenced to the residual protio solvent signal ${ }^{42}$ in the case of ${ }^{1} \mathrm{H}$ and ${ }^{13} \mathrm{C} .{ }^{19} \mathrm{~F}$ NMR spectra were 
referenced and reported relative to $\mathrm{CCl}_{3} \mathrm{~F}$ as an external standard following the recommended scale based on ratios of absolute frequencies ( $\equiv$ ) 43,44 The chemical shifts $(\delta)$ of all NMR spectra are reported in units of ppm, and the NMR spectra for all complexes are found in the Supporting Information (Figures S1 - S17). Midwest Microlab Inc. (Indianapolis, IN) performed all elemental analyses. Electronic absorption spectra were collected with an Ocean Optics Flame spectrometer, in a $1 \mathrm{~cm}$ path length quartz cuvette. Synthesis of [Zn] was carried out according to literature procedures. ${ }^{11,18}$

Cambridge Structural Database Deposition Numbers 2068727-2068732 contain the supplementary crystallographic data for this paper. These data are provided free of charge by the joint Cambridge Crystallographic Data Centre and Fachinformationszentrum Karlsruhe Access Structures service www.ccdc.cam.ac.uk/structures. Details on the X-ray crystallographic data and methods are given in the Supporting Information document.

\section{Electrochemical Methods}

Cyclic voltammetry was conducted with tetra( $n$-butylammonium) hexafluorophosphate $\left({ }^{n} \mathrm{Bu}_{4} \mathrm{~N}\right]^{+}\left[\mathrm{PF}_{6}\right]^{-}$; Sigma Aldrich, electrochemicalgrade) as the supporting electrolyte in dry, de-gassed acetonitrile or dimethylformamide $(0.1 \mathrm{M})$ inside a dry, $\mathrm{N}_{2}$-filled glovebox. Analyte concentration was $2.0 \mathrm{mM}$ unless otherwise noted. Measurements were taken using a standard three-electrode configuration and a Gamry Reference $600+$ potentiostat/galvanostat. The working electrode was the basal plane of highly-oriented pyrolytic graphite (HOPG) (Surface area: $0.09 \mathrm{~cm}^{2}$, GraphiteStore.com, Buffalo Grove, IL). The counter-electrode was a platinum wire (Kurt J. Lesker, Jefferson Hills, PA; 99.99\%, $0.5 \mathrm{~mm}$ diameter). A pseudo-reference electrode was used in the form of a silver wire immersed in electrolyte ( $\mathrm{CH}$ Instruments); separated from the working solution by a Vycor frit (Bioanalytical Systems, Inc.). Twice-sublimed ferrocene (Sigma-Aldrich) was added to the electrolyte solution prior to beginning each experiment and the midpoint of the ferrocenium/ferrocene couple (denoted $\mathrm{Fc}^{+/ 0}$ ) served as an external standard for comparison of the recorded potentials. The average peak-to-peak potential $\left(\Delta E_{\mathrm{p}}\right)$ for $\mathrm{Fc}^{+/ 0}$ across the experiments reported in this paper was $100.9 \mathrm{mV}$.

General Procedure for the Synthesis of [Zn,M]. In a dry, $\mathrm{N}_{2}$-filled glovebox, 1 equivalent of [Zn] was added to $\mathrm{CH}_{3} \mathrm{CN}$, resulting in a heterogenous suspension. To this, 1 equivalent of the corresponding metal-triflate salt, dissolved in $\mathrm{CH}_{3} \mathrm{CN}$, was added and stirred for 24 hours. A color change occurred after the first 30 minutes, shifting from darkorange to light orange or yellow, depending on the identity of the metal salt used. After 24 hours the solution was filtered, and the solvent removed in vacuo to give the desired compounds as free-flowing powders.

[Zn, Na]. Yield: 95\%. ${ }^{1} \mathrm{H}$ NMR (400 MHz, $\left.\mathrm{CD}_{3} \mathrm{CN}\right) \delta(\mathrm{ppm}): 8.89(\mathrm{~s}, 2 \mathrm{H})$ $7.76-7.70(\mathrm{~m}, 2 \mathrm{H}), 7.42-7.36(\mathrm{~m}, 2 \mathrm{H}), 7.05(\mathrm{dd}, J=8.1,1.6 \mathrm{~Hz}, 2 \mathrm{H})$ $6.90(\mathrm{dd}, J=7.7,1.6 \mathrm{~Hz}, 2 \mathrm{H}), 6.59(\mathrm{t}, J=7.9 \mathrm{~Hz}, 2 \mathrm{H}), 4.09-4.04(\mathrm{~m}, 4 \mathrm{H})$ $3.84-3.79(\mathrm{~m}, 4 \mathrm{H}), 3.61(\mathrm{~s}, 4 \mathrm{H}) .{ }^{13} \mathrm{C}\left\{{ }^{1} \mathrm{H}\right\} \mathrm{NMR}\left(126 \mathrm{MHz}, \mathrm{CD}_{3} \mathrm{CN}\right) \delta$ (ppm): 163.92, 151.82, 139.85, 128.97, 128.56, 119.96, 117.35, 115.18,

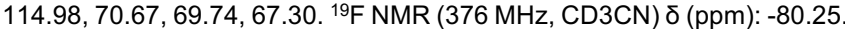
Electronic absorption spectrum in $\mathrm{CH}_{3} \mathrm{CN}\left(\mathrm{M}^{-1} \mathrm{~cm}^{-1}\right): 249$ (30200), 307 (27600), 408 (16300) nm.

Anal. Calcd for $\mathrm{C}_{27} \mathrm{H}_{24} \mathrm{~F}_{3} \mathrm{~N}_{2} \mathrm{NaO}_{9} \mathrm{SZn}$ ([Zn,Na]): C, 46.47; H, 3.47; N, 4.01; Found: C, 46.72; H, 3.79; N, 4.01

Vapor diffusion of diethyl ether $\left(\mathrm{Et}_{2} \mathrm{O}\right)$ into a dimethylformamide (DMF) solution containing $[\mathrm{Zn}, \mathrm{Na}]$ at $5^{\circ} \mathrm{C}$ afforded orange crystals suitable for $\mathrm{X}$ ray diffraction $(\mathrm{XRD})$ studies.

[Zn, Ca]. Yield: $88 \% .{ }^{1} \mathrm{H}$ NMR $\left(400 \mathrm{MHz}, \mathrm{CD}_{3} \mathrm{CN}\right) \delta(\mathrm{ppm}): 9.06(\mathrm{~s}, 2 \mathrm{H})$ $7.98-7.89(\mathrm{~m}, 2 \mathrm{H}), 7.57-7.48(\mathrm{~m}, 2 \mathrm{H}), 7.24(\mathrm{dd}, J=8.1,1.5 \mathrm{~Hz}, 2 \mathrm{H})$ $7.12(\mathrm{dd}, J=7.8,1.6 \mathrm{~Hz}, 2 \mathrm{H}), 6.79(\mathrm{t}, J=7.9 \mathrm{~Hz}, 2 \mathrm{H}), 4.32-4.25(\mathrm{~m}, 4 \mathrm{H})$ $4.14-4.07(\mathrm{~m}, 4 \mathrm{H}), 3.99(\mathrm{~s}, 4 \mathrm{H}) .{ }^{13} \mathrm{C}$ NMR $\left(126 \mathrm{MHz}, \mathrm{CD}_{3} \mathrm{CN}\right) \delta(\mathrm{ppm})$ $164.22,158.87,150.85,139.42,129.83,129.46,119.62,117.66,116.51$ 115.90, 70.93, 69.55, 67.57. ${ }^{19} \mathrm{~F} \mathrm{NMR}\left(471 \mathrm{MHz}, \mathrm{CD}_{3} \mathrm{CN}\right) \delta$ (ppm): -80.21 . Electronic absorption spectrum in $\mathrm{CH}_{3} \mathrm{CN}\left(\mathrm{M}^{-1} \mathrm{~cm}^{-1}\right)$ : 243 (22800), 307 (25700), 384 (11800) nm.

Anal. Calcd for $\mathrm{C}_{28} \mathrm{H}_{24} \mathrm{CaF}_{6} \mathrm{~N}_{2} \mathrm{O}_{12} \mathrm{~S}_{2} \mathrm{Zn}$ ([Zn,Ca]): C, 38.92; $\mathrm{H}, 2.80 ; \mathrm{N}$ 3.24; Calcd for $\mathrm{C}_{28} \mathrm{H}_{28} \mathrm{CaF}_{6} \mathrm{~N}_{2} \mathrm{O}_{14} \mathrm{~S}_{2} \mathrm{Zn}\left([\mathrm{Zn}, \mathrm{Ca}]+2 \mathrm{H}_{2} \mathrm{O}\right)$ : C, 37.36; $\mathrm{H}, 3.14$ $\mathrm{N}, 3.11$; Found: $\mathrm{C}, 37.75 ; \mathrm{H}, 3.26 ; \mathrm{N}, 3.11$. This analysis is consistent with the hygroscopic nature of this compound, and the observation of coordinated solvent in the solid-state structure of [ $\mathrm{Zn}, \mathrm{Ca}]$ (see $\mathrm{SI}$ ).
Vapor diffusion of diethyl ether $\left(\mathrm{Et}_{2} \mathrm{O}\right)$ into a methanol $(\mathrm{MeOH})$ solution containing $[\mathrm{Zn}, \mathrm{Ca}]$ at $5^{\circ} \mathrm{C}$ afforded crystals suitable for $\mathrm{X}$-ray diffraction (XRD) studies.

[Zn, Nd]. Yield: 93\%, ${ }^{1} \mathrm{H}$ NMR $\left(500 \mathrm{MHz}, \mathrm{CD}_{3} \mathrm{CN}\right) \delta$ (ppm): 19.72, 12.46 $10.21,9.25,8.90,6.45,5.94,4.01,1.37 .{ }^{13} \mathrm{C} \mathrm{NMR}\left(126 \mathrm{MHz}, \mathrm{CD}_{3} \mathrm{CN}\right) \delta$ (ppm): $167.64,155.99,152.65,143.68,134.51,132.50,120.93,120.18$ 118.90, 68.64, 61.47. ${ }^{19} \mathrm{~F}$ NMR (471 MHz, CD $\left.{ }_{3} \mathrm{CN}\right) \delta$ (ppm): -82.20. Electronic absorption spectrum in $\mathrm{CH}_{3} \mathrm{CN}\left(\mathrm{M}^{-1} \mathrm{~cm}^{-1}\right): 241$ (19500), 305 (26900), 334 (22400) nm

Anal. Calcd for $\mathrm{C}_{29} \mathrm{H}_{24} \mathrm{~F}_{9} \mathrm{~N}_{2} \mathrm{NdO}_{15} \mathrm{~S}_{3} \mathrm{Zn}([\mathrm{Zn}, \mathrm{Nd}]): \mathrm{C}, 31.18 ; \mathrm{H}, 2.17 ; \mathrm{N}$, 2.51; Found: C, 31.49; H, 2.43; N, 2.61.

Vapor diffusion of diethyl ether $\left(\mathrm{Et}_{2} \mathrm{O}\right)$ into a acetonitrile $\left(\mathrm{CH}_{3} \mathrm{CN}\right)$ solution containing $[\mathrm{Zn}, \mathrm{Nd}]$ at $25^{\circ} \mathrm{C}$ afforded crystals suitable for $\mathrm{X}$-ray diffraction (XRD) studies.

[Zn, Y]. Yield: 83\%. ${ }^{1} \mathrm{H}$ NMR (400 MHz, $\left.\mathrm{CD}_{3} \mathrm{CN}\right) \delta(\mathrm{ppm}): 9.11(\mathrm{~s}, 2 \mathrm{H})$, $8.01-7.93(\mathrm{~m}, 2 \mathrm{H}), 7.65-7.56(\mathrm{~m}, 2 \mathrm{H}), 7.40(\mathrm{dd}, J=8.1,1.4 \mathrm{~Hz}, 2 \mathrm{H})$ $7.32(\mathrm{dd}, J=8.1,1.5 \mathrm{~Hz}, 2 \mathrm{H}), 6.99(\mathrm{t}, J=8.0 \mathrm{~Hz}, 2 \mathrm{H}), 4.53(\mathrm{t}, J=4.9 \mathrm{~Hz}$, $4 \mathrm{H}), 4.30(\mathrm{t}, J=5.0 \mathrm{~Hz}, 4 \mathrm{H}), 4.23(\mathrm{~s}, 4 \mathrm{H}) .{ }^{13} \mathrm{C} \mathrm{NMR}\left(126 \mathrm{MHz}, \mathrm{CD}_{3} \mathrm{CN}\right) \delta$ (ppm): $164.11,149.97,130.31,120.16,117.90,71.11,70.75,69.21 .{ }^{19} \mathrm{~F}$ NMR $\left(471 \mathrm{MHz}, \mathrm{CD}_{3} \mathrm{CN}\right) \delta(\mathrm{ppm}):-80.18$. Electronic absorption spectrum in $\mathrm{CH}_{3} \mathrm{CN}\left(\mathrm{M}^{-1} \mathrm{~cm}^{-1}\right): 238$ (22300), 303 (28500), 332 (23100) nm.

Anal. Calcd for $\mathrm{C}_{29} \mathrm{H}_{24} \mathrm{~F}_{9} \mathrm{~N}_{2} \mathrm{O}_{15} \mathrm{~S}_{3} \mathrm{YZn}$ ([Zn,Y]): C, 32.80; $\mathrm{H}, 2.28 ; \mathrm{N}, 2.64$ Calcd for $\mathrm{C}_{41.5} \mathrm{H}_{53.5} \mathrm{~F}_{9} \mathrm{~N}_{5.5} \mathrm{O}_{19} \mathrm{~S}_{3} \mathrm{YZn}\left([\mathrm{Zn}, \mathrm{Y}]+3.5 \mathrm{DMF}+0.5 \mathrm{Et}_{2} \mathrm{O}\right) \mathrm{C}$ 36.79; H, 3.98; N, 5.69; Found: C, 37.18; H, 3.99; N, 5.74. The solid sample of $[\mathrm{Zn}, \mathrm{Y}]$ for analysis was prepared with crystals grown by vapor diffusion of $\mathrm{Et}_{2} \mathrm{O}$ into DMF; extensive drying to remove solvents associated with the isolated material resulted in decomposition, so the material was used asisolated.

Vapor diffusion of diethyl ether $\left(\mathrm{Et}_{2} \mathrm{O}\right)$ into a acetonitrile $\left(\mathrm{CH}_{3} \mathrm{CN}\right)$ solution containing $[\mathrm{Zn}, \mathrm{Nd}]$ at $-35^{\circ} \mathrm{C}$ afforded crystals suitable for X-ray diffraction (XRD) studies.

[Zn, Zn]. Yield: 93\%. ${ }^{1} \mathrm{H}$ NMR (400 MHz, $\left.\mathrm{CD}_{3} \mathrm{CN}\right) \delta$ (ppm): 9.04 (s, 2H) $7.94(\mathrm{dd}, J=6.2,3.4 \mathrm{~Hz}, 2 \mathrm{H}), 7.29(\mathrm{dd}, J=8.1,1.5 \mathrm{~Hz}, 2 \mathrm{H}), 7.24(\mathrm{dd}, J=$ $8.1,1.5 \mathrm{~Hz}, 2 \mathrm{H}), 6.96(\mathrm{t}, J=8.0 \mathrm{~Hz}, 2 \mathrm{H}), 4.33-4.26(\mathrm{~m}, 4 \mathrm{H}), 4.01-3.90$ $(\mathrm{m}, 4 \mathrm{H}), 3.77(\mathrm{~s}, 4 \mathrm{H}) .{ }^{13} \mathrm{C} N M R\left(126 \mathrm{MHz}, \mathrm{CD}_{3} \mathrm{CN}\right) \delta(\mathrm{ppm}): 165.39,162.99$, 149.77, 130.51, 129.27, 128.45, 120.56, 117.64, 116.76, 70.24, 69.09, 67.91. ${ }^{19} \mathrm{~F}$ NMR $\left(471 \mathrm{MHz}, \mathrm{CD}_{3} \mathrm{CN}\right) \delta(\mathrm{ppm}):-80.22$. Electronic absorption spectrum in $\mathrm{CH}_{3} \mathrm{CN}\left(\mathrm{M}^{-1} \mathrm{~cm}^{-1}\right)$ : 238 (31300), 310 (36700), (11800) nm.

Anal. Calcd for $\mathrm{C}_{28} \mathrm{H}_{24} \mathrm{~F}_{6} \mathrm{~N}_{2} \mathrm{O}_{12} \mathrm{~S}_{2} \mathrm{Zn}_{2}$ ([Zn, Zn]): C, 37.81; $\mathrm{H}, 2.72 ; \mathrm{F}, 12.82$; $\mathrm{N}, 3.15$; Calcd for $\mathrm{C}_{28} \mathrm{H}_{26} \mathrm{~F}_{6} \mathrm{~N}_{2} \mathrm{O}_{13} \mathrm{~S}_{2} \mathrm{Zn} 2\left([\mathrm{Zn}, \mathrm{Zn}]+\mathrm{H}_{2} \mathrm{O}\right): \mathrm{C}, 37.06 ; \mathrm{H}, 2.89$; $\mathrm{N}, 3.09$; Found: $\mathrm{C}, 36.94 ; \mathrm{H}, 3.06 ; \mathrm{N}, 2.78$. This analysis is consistent with the hygroscopic nature of this compound, as well as the observation of coordinated water in the solid-state structure $\left[\mathrm{Zn}, \mathrm{Zn}-\mathrm{OH}_{2}\right]$ (see $\mathrm{SI}$ ).

Vapor diffusion of diethyl ether $\left(\mathrm{Et}_{2} \mathrm{O}\right)$ into an acetonitrile $\left(\mathrm{CH}_{3} \mathrm{CN}\right)$ solution containing $[\mathrm{Zn}, \mathrm{Zn}]$ at $25^{\circ} \mathrm{C}$ afforded crystals suitable for $\mathrm{X}$-ray diffraction (XRD) studies.

\section{Acknowledgements}

The authors thank Dr. Justin Douglas and Sarah Neuenswander for assistance with NMR spectroscopy. This material was supported by the US Department of Energy, Office of Science, Office of Basic Energy Sciences through the Early Career Research Program (DE-SC0019169). This material is also based upon work by S.R.K. supported by the US National Science Foundation Graduate Research Fellowship through award DGE1940699 as well as the Madison \& Lila Self Graduate Fellowship at the University of Kansas.

Keywords: molecular electrochemistry $\cdot$ coordination chemistry - Lewis acids • zinc • macrocycles 


\section{References}

${ }^{1}$ (a) J. P. Krogman, B. M. Foxman and C. M. Thomas, J. Am. Chem. Soc. 2011, 133, 14582-14585. (b) B. G. Cooper, J. W. Napoline and C. M. Thomas, Catal. Rev.: Sci. Eng. 2012, 54, 1-40. (c) T. J. Mazzacano and N. P. Mankad, J. Am. Chem. Soc. 2013, 135, 17258-17261.

2 (a) P. Sharma, D. R. Pahls, B. L. Ramirez, C. C. Lu and L. Gagliardi, Inorg. Chem. 2019, 58, 10139-10147. B. E. Klamm, T. E. Albrecht-Schmitt, R. E. Baumbach, B. S. Billow, F. D. White, S. A. Kozimor, B. L. Scott and A. M. Tondreau, Inorg. Chem. 2020, 59, 8642-8646.

${ }^{3}$ C. P. Horwitz and Y. Ciringh, Inorg. Chim. Acta 1994, 225, 191200.

${ }^{4}$ A. Kumar and J. D. Blakemore, J. Am. Chem. Soc. 2021, 60, 1107-1115.

${ }^{5}$ D. Lionetti, M. W. Day and T. Agapie, Chem. Sci. 2013, 4, 785790.

${ }^{6}$ (a) J. P. McEvoy and G. W. Brudvig, Chem. Rev. 2006, 106, 4455-4483. (b) J. Yano and V. Yachandra, Chem. Rev. 2014, 114, 4175-4205.

${ }^{7}$ (a) J. S. Kanady, E. Y. Tsui, M. W. Day and T. Agapie, Science 2011, 333, 733-736. (b) E. Y. Tsui and T. Agapie, Proc. Natl. Acad. Sci. U. S. A. 2013, 110, 10084-10088. (c) E. Y. Tsui, J. S. Kanady and T. Agapie, Inorg. Chem. 2013, 52, 13833-13848.

${ }^{8}$ (a) S. Bang, Y.-M. Lee, S. Hong, K.-B. Cho, Y. Nishida, M. S. Seo, R. Sarangi, S. Fukuzumi and W. Nam, Nat. Chem. 2014, 6, 934-940. (b) Y. J. Park, J. W. Ziller and A. S. Borovik, J. Am. Chem. Soc. 2011, 133, 9258-9261. (c) D. C. Lacy, Y. J. Park, J. W. Ziller, J. Yano and A. S. Borovik, J. Am. Chem. Soc. 2012, 134, 17526-17535.

${ }^{9}$ (a) S.-M. Yiu, W.-L. Man and T.-C. Lau, J. Am. Chem. Soc. 2008, 130, 10821-10827. (b) M. R. Kita and A. J. M. Miller, J. Am. Chem. Soc. 2014, 136, 14519-14529. (c) J. A. Buss, D. G. VanderVelde and T. Agapie, J. Am. Chem. Soc. 2018, 140, 10121-10125.

${ }^{10}$ A. Kumar, D. Lionetti, V. W. Day and J. D. Blakemore, J. Am. Chem. Soc. 2020, 142, 3032-3041.

${ }^{11}$ A. Kumar, D. Lionetti, V. W. Day and J. D. Blakemore, Chem. - Eur. J. 2018, 24, 141-149.

12 (a) P. L. Arnold, D. Patel, C. Wilson and J. B. Love, Nature 2008, 451, 315. (b) P. L. Arnold, J. B. Love and D. Patel, Coord. Chem. Rev. 2009, 253, 1973-1978. (c) S. Fortier and T. W. Hayton, Coord. Chem. Rev. 2010, 254, 197-214. (d) D. D. Schnaars, G. Wu and T. W. Hayton, J. Am. Chem. Soc. 2011, 50, 9642-9649.

${ }^{13}$ (a) W. Kaim, Eur. J. Inorg. Chem. 2012, 2012, 343-348. (b) R. Eisenberg and H. B. Gray, Inorg. Chem. 2011, 50, 97419751.

${ }^{14}$ T. P. Brewster, T. H. Nguyen, Z. Li, W. T. Eckenhoff, N. D. Schley and N. J. DeYonker, J. Am. Chem. Soc. 2018, 57, 1148-1157.

15 (a) A. H. Reath, J. W. Ziller, C. Tsay, A. J. Ryan and J. Y. Yang, J. Am. Chem. Soc. 2017, 56, 3713-3718.

${ }^{16}$ D. D. Perrin, Ionisation Constants of Inorganic Acids and Bases in Aqueous Solution, Pergamon Press, New York, 1982.

17 C. J. Van Staveren, D. E. Fenton, D. N. Reinhoudt, J. Van Eerden and S. Harkema, J. Am. Chem. Soc. 1987, 109, 3456-3458.
${ }^{18}$ C. J. Van Staveren, J. Van Eerden, F. C. J. M. Van Veggel, S. Harkema and D. N. Reinhoudt, J. Am. Chem. Soc. 1988. 110, 4994-5008.

19 (a) P. Zanello, A. Cinquantini, P. Guerriero, S. Tamburini and P. A. Vigato, Inorg. Chim. Acta 1986, 117, 91-96. (b) N Brianese, U. Casellato, S. Tamburini, P. Tomasin and P. A. Vigato, Inorg. Chim. Acta 1999, 293, 178-194.

${ }^{20}$ (a) H. W. Milburn, M. R. Truter and B. L. Vickery, Chem. Commun. 1968, 1188. (b) M. R. Truter, Alkali Metal Complexes with Organic Ligands (Berlin, Heidelberg) 1973, pp. 71-111.

${ }^{21}$ (a) S. J. Gruber, C. M. Harris and E. Sinn, Inorg. Nucl. Chem. Lett. 1967, 3, 495-499. (b) S. J. Gruber, C. M. Harris and E. Sinn, Inorg. Chem. 1968, 7, 268-273. (c) S. J. Gruber, C. M. Harris and E. Sinn, Inorg. Nucl. Chem. Lett. 1968, 4, 107-111.

22 C. Floriani, F. Calderazzo and L. Randaccio, J. Chem. Soc., Chem. Commun. 1973, 384-385.

${ }^{23}$ (a) T. Chantarojsiri, J. W. Ziller and J. Y. Yang, Chem. Sci. 2018, 9, 2567-2574. (b) T. Chantarojsiri, A. H. Reath and J. Y. Yang, Angew. Chem. Int. Ed. 2018, 57, 14037-14042.

${ }^{24}$ C. R. Groom, I. J. Bruno, M. P. Lightfoot and S. C. Ward, Acta Cryst. Sect. B 2016, 72, 171-179.

${ }^{25}$ (a) F. C. J. M. Van Veggel, S. Harkema, M. Bos, W. Verboom, C. J. Van Staveren, G. J. Gerritsma and D. N. Reinhoudt, Inorg. Chem. 1989, 28, 1133-1148. (b) M. Yamami, H. Furutachi, T. Yokoyama and H. Ōkawa, Inorg. Chem. 1998, 37, 6832-6838.

${ }^{26}$ (a) E. C. Escudero-Adán, M. M. Belmonte, E. Martin, G. Salassa, J. Benet-Buchholz and A. W. Kleij, J. Org. Chem. 2011, 76, 5404-5412. (b) M. Lacaze, N. Saffon-Merceron, F. Silly and J. Bonvoisin, J. Mol. Struct. 2021, 1223, 129319.

${ }^{27}$ (a) X. Yang, R. A. Jones, Q. Wu, M. M. Oye, W.-K. Lo, W.-K. Wong and A. L. Holmes, Polyhedron 2006, 25, 271-278. (b) L.-y. Wu, D.-d. Fan, X.-q. Lü and R. Lu, Chin. J. Polymer Sci. 2014, 32, 768-777. Q. Shi, J. Yang and X. Lü, Inorg. Chem. Commun. 2015, 59, 61-62.

${ }^{28}$ M. Mastalerz and I. M. Oppel, Eur. J. Org. Chem. 2011, 2011, 5971-5980.

${ }^{29}$ (a) S. R. Korupoju, N. Mangayarkarasi, S. Ameerunisha, E. J. Valente and P. S. Zacharias, J. Chem. Soc., Dalton Trans. 2000, 2845-2852. (b) S. Ponsico, H. Gulyas, M. MartínezBelmonte, E. C. Escudero-Adán, Z. Freixa and P. W. N. M. van Leeuwen, Dalton Trans. 2011, 40, 10686-10697.

${ }^{30}$ For example, among many: (a) W.-K. Wong, H. Liang, W.-Y. Wong, Z. Cai, K.-F. Li and K.-W. Cheah, New. J. Chem. 2002, 26, 275-278. (b) J. B. S. Linden-Leibeszeit, S. V. Eliseeva, N. Chaudhary, M. Zeller, S. Petoud and E. R. Trivedi, Eur. J. Inorg. Chem. 2020, 2020, 75-78. (c) J. Long, M. S. Ivanov, V. A. Khomchenko, E. Mamontova, J.M. Thibaud, J. Rouquette, M. Beaudhuin, D. Granier, R. A. S. Ferreira, L. D. Carlos, B. Donnadieu, M. S. C. Henriques, J. A. Paixão, Y. Guari and J. Larionova, Science 2020, 367, 671-676.

${ }^{31}$ R. D. Shannon, Acta Cryst. Sect. A 1976, 32, 751-767.

32 Limited reports regarding the reductive electrochemical properties of zinc(II) salophen complexes are available; very few or none are available for heterobimetallic derivatives. A few reports suggest one or more reduction events are accessible for monometallic zinc species, but the available data is inconclusive due to involvement of 
chemically irreversible behaviors. For example, see: $F$. Dumur, E. Contal, G. Wantz and D. Gigmes, Eur. J. Inorg. Chem. 2014, 2014, 4186-4198.

${ }^{33}$ A. J. Bard, R. Parsons and J. Jordan, Standard Potentials in Aqueous Solution, M. Dekker, New York, 1985.

${ }^{34}$ D. J. Sconyers and J. D. Blakemore, Analyst 2020, 145, 466477.

35 J. M. Savéant and C. Costentin, Elements of Molecular and Biomolecular Electrochemistry, An Electrochemical Approach to Electron Transfer Chemistry, Wiley, Hoboken, NJ, 2019.

${ }^{36}$ A. A. Isse, A. Gennaro and E. Vianello, Electrochim. Acta 1992, 37, 113-118.

37 J. Andrez, V. Guidal, R. Scopelliti, J. Pécaut, S. Gambarelli and M. Mazzanti, J. Am. Chem. Soc. 2017, 139, 86288638.

${ }^{38}$ A. J. Bard and L. R. Faulkner, Electrochemistry: Fundamentals and Applications, John Wiley and Sons Inc. Hoboken, 2001.

${ }^{39}$ R. S. Nicholson, Anal. Chem. 1965, 37, 1351-1355.
${ }^{40}$ H. Y. V. Ching, E. Anxolabéhère-Mallart, H. E. Colmer, C. Costentin, P. Dorlet, T. A. Jackson, C. Policar and M. Robert, Chem. Sci. 2014, 5, 2304-2310.

${ }^{41}$ W. Nie, D. E. Tarnopol and C. C. L. McCrory, J. Am. Chem. Soc. 2021, in press, doi: 10.1021/jacs.0c09357

${ }^{42}$ Fulmer, G. R.; Miller, A. J. M.; Sherden, N. H.; Gottlieb, H. E.; Nudelman, A.; Stoltz, B. M.; Bercaw, J. E.; Goldberg, K. I. NMR Chemical Shifts of Trace Impurities: Common Laboratory Solvents, Organics, and Gases in Deuterated Solvents Relevant to the Organometallic Chemist. Organometallics 2010, 29, 2176-2179.

${ }^{43}$ Harris, R. K.; Becker, E. D.; Cabral de Menezes, S. M.; Goodfellow, R.; Granger, P. NMR nomenclature. Nuclear spin properties and conventions for chemical shifts (IUPAC Recommendations 2001). Pure Appl. Chem. 2001, 73, 1795-1818.

${ }^{44}$ Harris, R. K.; Becker, E. D.; Cabral de Menezes, S. M.; Granger, P.; Hoffman, R. E.; Zilm, K. W. Further conventions for NMR shielding and chemical shifts (IUPAC Recommendations 2008). Pure Appl. Chem. 2008, 80, 59-84. 


\section{Entry for the Table of Contents}

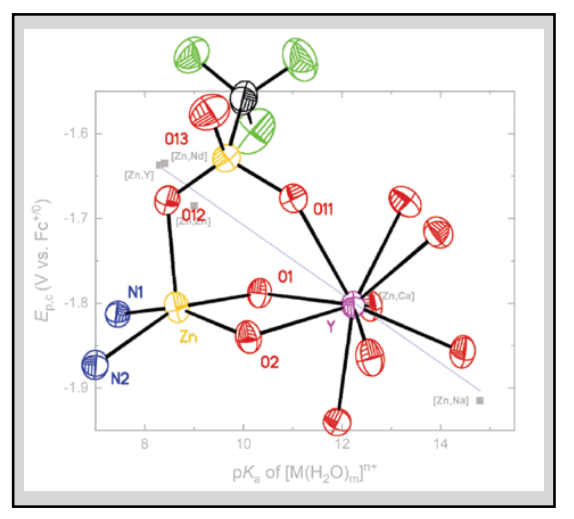

Let's Get Together. Incorporation of redox-inactive cations is a recognized strategy for tuning electroactive molecules and materials, but understanding the influence of multiple redox-inactive ions remains challenging. Here, the electrochemical properties of a series of bimetallic zinc-containing macrocyclic complexes are interpreted in the context of their structural properties, revealing the influences of the Lewis acids that could be signatures for interpretation of tuning effects in other systems.

Institute and/or researcher Twitter usernames: @KUChemistry, @UnivOfKansas, @KUCollege 